Ferrata Storti Foundation

\title{
Combination peptide immunotherapy suppresses antibody and helper T-cell responses to the major human platelet autoantigen glycoprotein Ilb/IIla in HLA-transgenic mice
}

Haematologica 2019

Volume 104(5):1074-1082

\section{Correspondence:}

ROBERT N. BARKER

r.n.barker@abdn.ac.uk

Received: September 4, 2017.

Accepted: November 29, 2018.

Pre-published: December 4, 2018.

doi:10.3324/haematol.2017.179424

Check the online version for the most updated information on this article, online supplements, and information on authorship \& disclosures: www. haematologica.org/content/104/5/1074

(C)2019 Ferrata Storti Foundation

Material published in Haematologica is covered by copyright. All rights are reserved to the Ferrata Storti Foundation. Use of published material is allowed under the following terms and conditions:

https://creativecommons.org/licenses/by-nc/4.0/legalcode. Copies of published material are allowed for personal or internal use. Sharing published material for non-commercial purposes is subject to the following conditions:

https://creativecommons.org/licenses/by-nc/4.0/legalcode, sect. 3. Reproducing and sharing published material for commercial purposes is not allowed without permission in writing from the publisher.

\section{Lindsay S. Hall, ${ }^{1,2}$ Charlotte S. Lennon, ${ }^{1}$ Andrew M. Hall, ${ }^{1}$ \\ Stanislaw J. Urbaniak, ${ }^{1,2}$ Mark A. Vickers ${ }^{1,2^{*}}$ and Robert N. Barker ${ }^{1^{*}}$}

${ }^{1}$ Institute of Medical Sciences, Ashgrove Road West, University of Aberdeen and ${ }^{2}$ Scottish National Blood Transfusion Service, Foresterhill Road, Aberdeen, UK

*MAV and RNB are joint senior authors

\section{ABSTRACT}

Dlatelet destruction in immune thrombocytopenia is caused by autoreactive antibody and T-cell responses, most commonly directed against platelet glycoprotein IIb/IIIa. Loss of self-tolerance in the disease is also associated with deficient activity of regulatory $\mathrm{T}$ cells. Having previously mapped seven major epitopes on platelet glycoprotein IIIa that are recognized by helper T cells from patients with immune thrombocytopenia, the aim was to test whether peptide therapy with any of these sequences, alone or in combination, could inhibit responses to the antigen in humanized mice expressing HLA-DR15. None of the individual peptides, delivered by a putative tolerogenic regimen, consistently suppressed the antibody response to subsequent immunization with human platelet glycoprotein IIb/IIIa. However, the combination of glycoprotein IIIa peptides aa6-20 and aa711-725, which contain the predominant helper epitopes in patients and elicited the strongest trends to suppress when used individually, did abrogate this response. The peptide combination also blunted, but did not reverse, the ongoing antibody response when given after immunization. Suppression of antibody was associated with reduced splenocyte $\mathrm{T}$-cell responsiveness to the antigen, and with the induction of a regulatory $\mathrm{T}$-cell population that is more responsive to the peptides than to purified platelet glycoprotein IIb/IIIa. Overall, these data demonstrate that combinations of peptides containing helper epitopes, such as platelet glycoprotein IIIa aa6-20 and aa711725 , can promote in vivo suppression of responses to the major antigen implicated in immune thrombocytopenia. The approach offers a promising therapeutic option to boost T-cell regulation, which should be taken forward to clinical trials.

\section{Introduction}

Immune thrombocytopenia (ITP) is a bleeding disorder defined by an isolated thrombocytopenia and caused by immune responses against self-antigens expressed on platelets and/or megakaryocytes. ${ }^{1.4}$ The most commonly targeted autoantigen is platelet glycoprotein (GP) IIb/IIIa, with responses against other glycoproteins such as GPIb/IX or GPIV seen in a minority of cases..$^{5.7}$ GPIIb/IIIa, also known as integrin $\alpha_{\text {It }} \beta_{3}$, functions as the main fibrinogen and von Willebrand factor receptor and is highly expressed on the plasma membranes of platelets. Characterization of this major autoantigen is a key step in the development of specific immunotherapy that could selectively inhibit the pathogenic responses against platelets.'

Platelet destruction in ITP is believed to be mediated by IgG autoantibodies, which opsonize platelet and/or megakaryocyte surfaces, ${ }^{8,9}$ leading to clearance via Fcy-receptors on macrophages, predominantly in bone marrow, spleen and liver. T- 
cell cytotoxicity has also been demonstrated against platelets and megakaryocytes. ${ }^{10,11}$ Class switching and somatic mutation of the autoantibodies ${ }^{12}$ indicate that their production is T-dependent, in line with the finding that autoreactive $\mathrm{CD}^{+}$helper $\mathrm{T}$ (Th) cells specific for the corresponding platelet antigens are activated in the disease.,13-15 Evidence has accumulated that the loss of peripheral tolerance in ITP reflects an imbalance between regulatory and effector $\mathrm{CD}^{+}$T-cell activity, with, in particular, impairment of the suppressive function of the $\mathrm{CD} 25^{+} \mathrm{FoxP}^{+}$regulatory T (Treg) subset., ${ }^{2,16}$ ITP therefore fits the paradigm emerging in other autoantibody-mediated diseases, in which pathogenic responses are helper-dependent and arise and/or are sustained due to inadequate Treg suppression. ${ }^{19-21}$

The current first-line treatment for ITP, steroids, inhibits autoantibody production and platelet degradation by inducing generalized immunosuppression. ${ }^{23,24}$ However, the numerous side effects of this treatment include infection and cardiovascular disease, which are more frequent causes of death than bleeding in ITP patients. ${ }^{25}$ Second-line treatments, for instance rituximab to deplete B cells, immunoglobulin infusions or splenectomy, are also nonspecific and typically further intensify immunosuppression. Third-line thrombopoietic agents are expensive, and although they can induce lasting remission in some patients $^{26}$ and induce immune tolerance to platelet autoantigens in a murine model of ITP, ${ }^{27}$ these effects are not fully understood, and longer term side effects have yet to be fully reported. ${ }^{23,24}$ In contrast to previous untargeted approaches, antigen-specific immunotherapy offers the prospect of rebalancing pathogenic $\mathrm{CD}^{+}{ }^{+} \mathrm{Th}$ and Treg responses, without compromising the rest of the immune system. ${ }^{28-32}$ Precedents in models of other immune-mediated diseases demonstrate that this can be achieved by appropriate administration of short, synthetic peptides containing $\mathrm{CD}^{+} \mathrm{T}$-cell epitopes from the respective target antigens, with peptide products being tested in clinical trials for the treatment of a number of conditions, including type I diabetes, multiple sclerosis and rheumatoid arthritis. ${ }^{28-32}$ The approach induces immune regulation, which, in addition to suppressing inflammatory $\mathrm{T}$-cell responses, also has the potential to inhibit helper-dependent antibody production, as demonstrated by the success of peptide therapy in blocking IgG responses to the $\mathrm{RhD}$ blood group protein in a humanized murine model..$^{33,34}$ Once peptides that span major T-cell epitopes have been mapped, key requirements for effective immunotherapy include delivery of these sequences in soluble form, in the absence of any adjuvant material. ${ }^{28,29,34,35}$ Despite an initial focus on mucosal administration of peptides, a variety of routes are now known to be effective, including subcutaneous. ${ }^{29,31,34}$

The fine specificity of autoreactive Th cells in ITP has been characterized with a view to developing specific peptide therapy that restores helper tolerance and avoids longterm immunosuppressive steroid treatment or splenectomy. When a panel of 15-mer peptides spanning the entire length of GPIIIa was screened for helper epitopes, particular sequences were found to elicit recall responses by CD4+ T cells from patients with ITP. Despite variation between different cases, seven GPIIIa peptides (aa6-20, aa331-345, aa361-375, aa421-435, aa591-605, aа661-675 and aa711$725)$ were commonly recognized, with one or more eliciting responses by $\mathrm{T}$ cells from $84 \%$ of patients. Of these peptides, two predominated (aa6-20 and aa711-725), with either or both being stimulatory in $65 \%$ of patients.

The aim of the current work, and the next step in developing specific immunotherapy for ITP patients, was to test and compare the efficacy of the seven dominant GPIIIa peptides, particularly aa6-20 and aa711-725, in suppressing responses to GPIIb/IIIa in a pre-clinical animal model. In order to replicate restriction and peptide-binding preferences of the human major histocompatibility complex (MHC), the model used was a humanized transgenic mouse expressing HLA-DR rather than murine class II molecules. A strain transgenic for HLA-DR15 was chosen for these proof-of-principle studies, since it is an established model for investigating responses restricted by human class II, ${ }^{33,34}$ and, although there is no consensus as to whether certain class II alleles predispose to, or protect

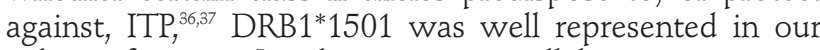
cohort of patients ${ }^{7}$ and is a common allele in many populations. We demonstrate that sequences aa6-20 and aa711725 in combination are effective in suppressing Th and IgG antibody responses to immunization of the mice with GPIIIa, and that this effect is associated with induction of a Treg population.

\section{Methods}

\section{Purification of glycoprotein IIb/IIla}

GPIIb/IIIa was purified as previously reported, ${ }^{38}$ with minor modifications. In brief, apheresed platelets (provided by the

Table 1. GPIIla immunodominant peptides. Peptides, previously reported to contain Th epitopes that are immunodominant in patients with immune thrombocytopenia, ${ }^{7}$ were manufactured to their wild-type sequence or extended using an arginine-lysine wrapper to improve manufacturability and solubility.

\begin{tabular}{lccc} 
Peptide nomenclature & GPIIla sequence & Amino acids & Modified to improve manufacture \\
P2 & TTRGVSSCQQCLAVS-acid & aa6-20 & No \\
P44 & KRGVLSMDSSNVLQLIVRK-acid & aa331-345 & Yes* $^{*}$ \\
P47 & DLPEELSLSFNATCL-acid & aa361-375 & No \\
P53 & FKDSLIVQVTFDCDC-acid & aa421-435 & No \\
P70 & PGSYGDTCEKCPTCP-acid & aa591-605 & No \\
P77 & DDCWRFQYYEDSSG-acid & aa661-675 & No \\
\hline P82 & KRALLIWKLLITIHDRKRK-acid & aa711-725 & Yes* \\
\hline
\end{tabular}

* Modified by inclusion of an RK wrapper - added in bold. 
Scottish National Blood Transfusion Service) were incubated in 50 $\mathrm{mM}$ octylglucopyranoside (Abcam, Cambridge, UK). GPIIb/IIIa was extracted from the supernatant onto sepharose beads displaying GPIIIa-specific peptide GRGDSPK (Cambridge Research Biochemicals, Billingham, UK), and eluted with peptide GRGDSP (Merck Chemicals, Nottingham, UK). The purity of the eluted GPIIb/IIIa preparation was confirmed by western blotting.

\section{Peptides}

Peptides containing GPIIla epitopes (Table 1) were manufactured to $>95 \%$ purity (Cambridge Research Biochemicals). To achieve solubility in aqueous media, which is a key property for efficient production and purification, as well as for efficacy in immunotherapy, ${ }^{28,29,34,35}$ two sequences, P44 (aa331-345) and P82 (aa711-725), were extended by an arginine-lysine wrapper.

\section{Mouse immunization and peptide treatment}

Animal work was approved by the University of Aberdeen Ethical Review Committee and authorized by the UK Government Home Office (project license 70/8744). Mice transgenic for HLA-DRA1*1010 and HLA-DRB1*1501, which express HLA-DR15 but not murine MHC class II, were originally supplied by Professor Daniel Altman (Imperial College London, UK) ${ }^{39}$ and maintained as a genotyped and phenotyped colony at the University of Aberdeen.

Anti-platelet GPIIb/IIIa responses were induced by subcutaneous injection of mice with $10 \mu \mathrm{g}$ purified GPIIb/IIIa antigen, repeated 2 weeks later. Mice immunized with control antigen received injections of ovalbumin (Sigma, Poole, UK) instead of GPIIb/IIIa. Mice were treated with GPIIIa peptides by subcutaneous injection, receiving $100 \mu \mathrm{g}$ of each peptide selected, either alone or in combination.

\section{Blood sampling and tissue preparation}

Blood samples were collected into heparinized tubes. Single cell suspensions of splenocytes were prepared using the Miltenyi spleen dissociation $\mathrm{kit}^{\mathrm{TM}}$ and gentleMacs octo-dissociator ${ }^{\mathrm{TM}}$
(Miltenyi Biotec, Bisley, UK). Where required, Treg were depleted from splenocytes using the Miltenyi $\mathrm{CD} 4^{+} \mathrm{CD} 25^{+}$regulatory $\mathrm{T}$-cell isolation kit.

\section{Cell culture}

As previously described, ${ }^{33,34}$ splenocytes were cultured at $1.25 \times 10^{6} \mathrm{cells} / \mathrm{mL}$ in $\alpha \mathrm{MEM}$ (Sigma, Poole, UK), supplemented with $0.5 \%$ syngeneic serum. Cultures were stimulated with purified GPIIb/IIIa antigen at a final concentration of $1 \mu \mathrm{g} / \mathrm{mL}$, or with the control antigen ovalbumin at a final concentrations of 10 $\mu \mathrm{g} / \mathrm{mL}$, or with Dynabeads ${ }^{\mathrm{TM}}$ Mouse T-Activator CD3/CD28 (Invitrogen, Fisher Scientific, UK), or with peptides, either individually or in combination, at final concentrations of $10 \mu \mathrm{g} / \mathrm{mL}$ each.

\section{Flow cytometry}

After 5 days of culture, splenocytes were stained with fluorescein isothiocyanate-conjugated anti-CD4 (eBioscience, Fisher Scientific, Loughborough, UK) and Pacific blue-conjugated antiCD25 (Biolegend, London, UK) antibodies, permeabilized and stained with phycoerythrin-conjugated anti-FoxP3 (eBioscience). Samples were analyzed on an LSR Fortessa ${ }^{\mathrm{TM}}$ flow cytometer (BD Bioscience, Oxford, UK) using FACSDiva ${ }^{\mathrm{TM}}$ software. Regulatory $\mathrm{T}$ cells were defined as $\mathrm{CD} 4^{+} \mathrm{CD} 25^{+} \mathrm{FoxP3}^{+}{ }^{40}$

\section{Proliferation assays and cytokine enzyme-linked immunosorbent assays}

As described elsewhere, after 5 days of culture, ${ }^{33-35}$ splenocyte proliferation was estimated from ${ }^{3} \mathrm{H}$-thymidine incorporation and presented as a stimulation index, representing the ratio of counts per minute (CPM) in stimulated versus unstimulated wells (with a ratio $>3$ taken as being significant ${ }^{41}$ ). Interleukin-10 (IL-10) production in cultures was measured by enzyme-linked immunosorbent assay (ELISA) (antibody pairs from BD Bioscience).

\section{Measurement of serum antibody specific for glycoprotein IIb/IIla or control antigen}

ELISA to measure murine IgG antibodies specific for GPIIb/IIIa,
A

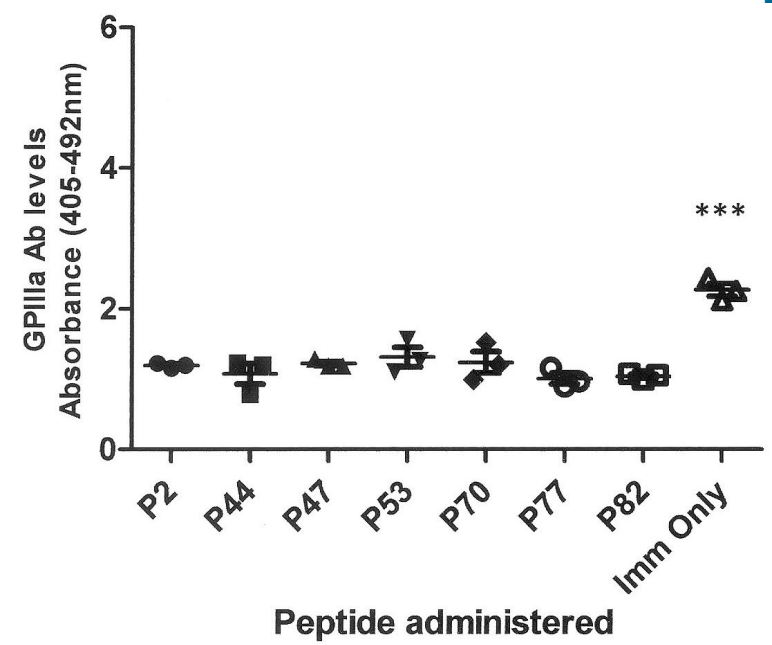

B

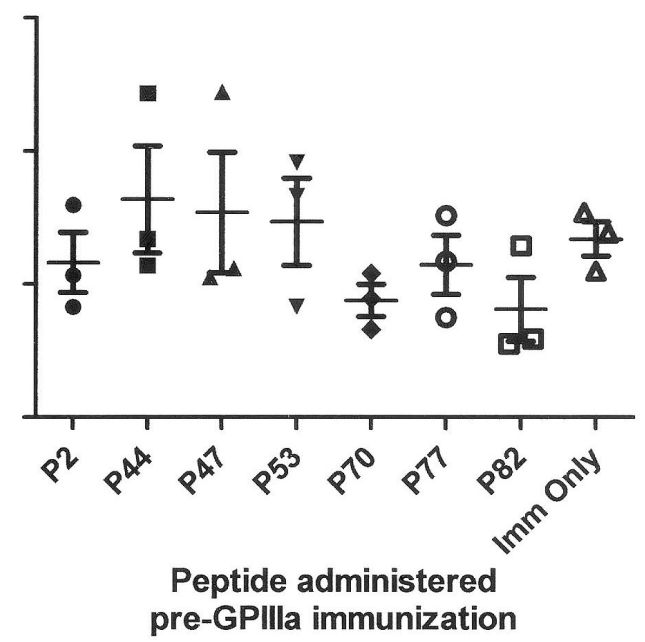

Figure 1. Treatment of HLA-DR15 transgenic mice with individual glycoprotein Illa peptides containing Th epitopes neither elicits antibody specific for glycoprotein $\mathrm{Ilb} / \mathrm{Illa}$, nor consistently blocks the antibody response to immunization with purified glycoprotein Ilb/IIla. (A) Purified human GPIlb/Illa or individual peptides were administered by subcutaneous injection to HLA-DR15 transgenic mice on days 0 and 14, with the levels of plasma IgG antibodies reactive to purified GPIIb/IIla measured by enzyme-linked immunosorbent assay (ELISA) on day 28. (B) Individual peptides were administered to mice on days 0 and 14 , followed by purified GPIlb/IIla on days 28 and 42, with IgG antibodies measured by ELISA on day 70 . Data points represent results from individual mice ( $\mathrm{n}=3$ per group). $* * * P<0.0001$, one way analysis of variance. Ab: antibody. 
or for the control antigen ovalbumin, were adapted from a published method..$^{38}$ Microtiter plates (Nunc, Fisher Scientific, Loughborough, UK) were coated with either purified GPIIb/IIIa or ovalbumin, incubated with plasma samples diluted 1:20 in phosphate-buffered saline, probed with anti-mouse IgG conjugated to alkaline phosphatase (Invitrogen, Fisher Scientific), and developed with $p$-nitrophenyl phosphate substrate (Sigma). The absorbance was measured at $405 \mathrm{~nm}$.

\section{Statistical analyses}

Statistical tests were performed using SigmaPlot (SyStat Software).

\section{Results}

Seven peptides (Table 1) containing GPIIIa epitopes that are commonly recognized by Th cells from patients with ITP and are, therefore, candidates for inclusion in an immunotherapeutic product ${ }^{7}$ were screened for their effects on immunity to GPIIb/IIIa in HLA-DR15 transgenic mice. The genetically modified strain was used, not to ensure responses to immunization with human GPIIb/IIIa, but in order to recapitulate in vivo the presentation of particular GPIIIa peptides by human MHC class II molecules. GPIIIa peptides containing the T-cell epitopes that had been mapped in ITP patients would not necessarily be presented by murine class II molecules to modify responses of wild-type mice to GPIIb/IIIa, and any effects would not be of direct relevance to human disease. The administration of the peptides, given in soluble form via the subcutaneous route in the absence of adjuvant signals, was designed to favor induction of regulatory versus effector responses. ${ }^{28,29,34,35}$

\section{Stimulation of antibody responses to glycoprotein IIb/IIla}

It was first necessary to confirm that HLA-DR15 transgenic mice could mount an antibody response to GPIIb/IIIa after immunization with the purified full-length antigen, and that no such response was elicited by of any of the seven candidate peptides considered as putative suppressive treatment. Purified GPIIb/IIIa or individual GPIIIa peptides were administered to mice, with IgG anti-
A

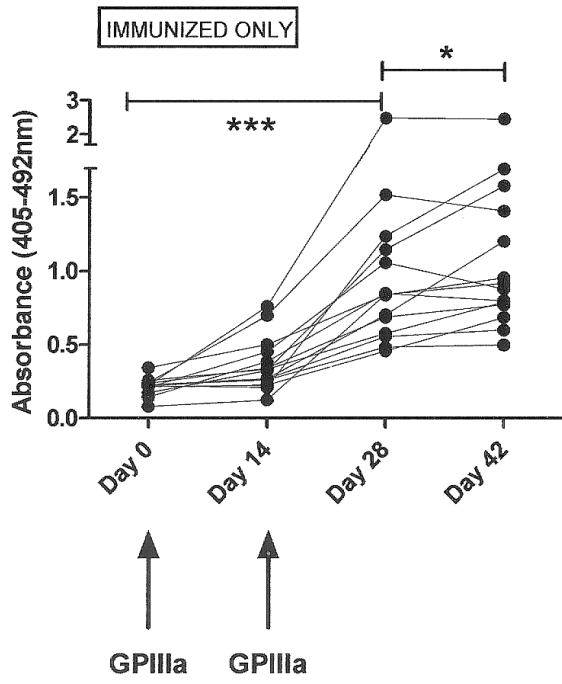

B

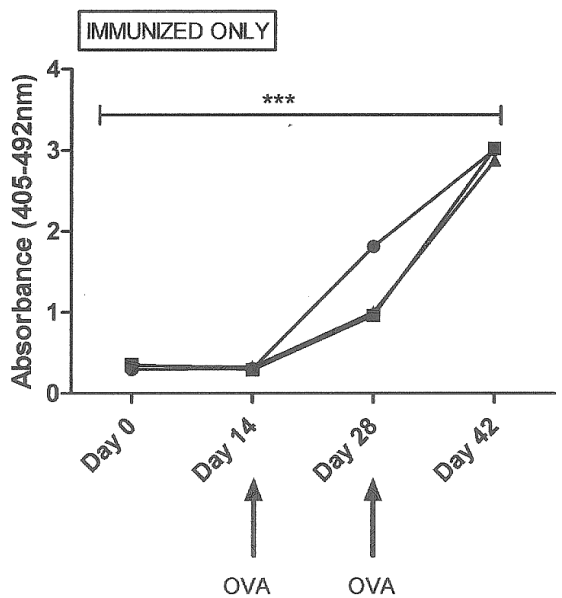

INHIBITION
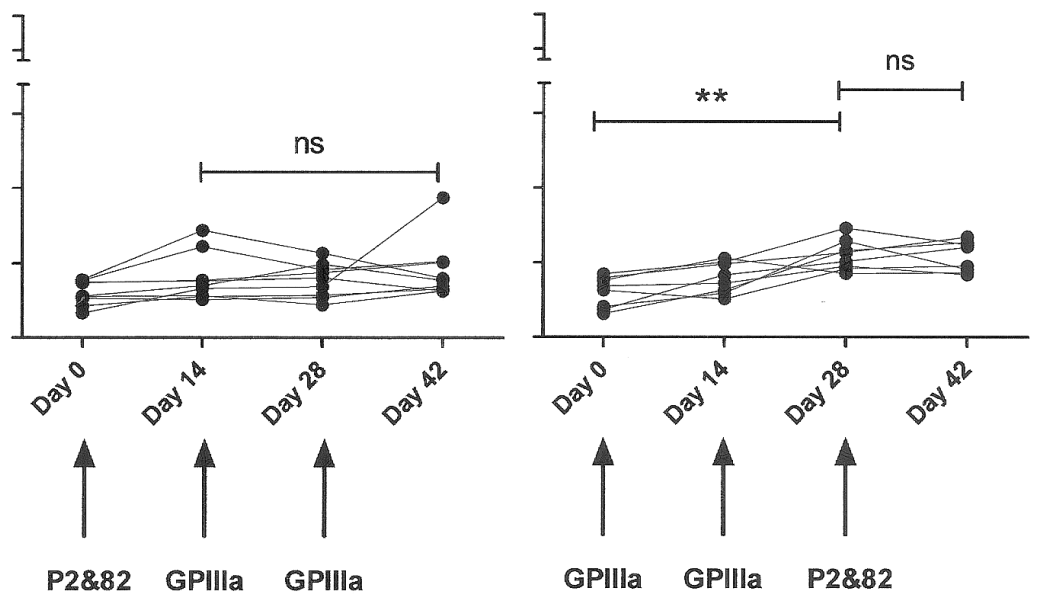

Figure 2. Treatment of HLA-DR15 transgenic mice with a combination of glycoprotein IIla peptides containing Th epitopes inhibits antibody responses to immunization with purified glycoprotein Ilb/IIla, but not the control antigen ovalbumin. Levels of plasma IgG antibodies reactive to (A) the antigen purified GPIIb/IIla or (B) ovalbumin were measured by enzyme-linked immunosorbent assay in serial plasma samples from mice only immunized with GPIlb/llla or ovalbumin (immunized only); or pre-treated with a mixture of GPIlb/Illa peptides 2 (aa6-20) and 82 (aa711-725) before immunization (prevention); or given the mixture of peptides after immunization (inhibition). Arrows indicate timing of peptide treatment (P2\&82) and immunizations with GPIIb/IIla (GPIIla) or ovabumin (OVA) Lines connect serial data points from individual mice: (A) immunized only $(n=14)$, prevention $(n=9)$, inhibition $(n=8)$, tolerized $(n=3)$; $(B)$ immunized only $(n=3)$, prevention $(n=3)$. $* * * P<0.0005, * * P<0.005, * P<0.05$, paired $t$ test, ns indicates not significant. 
bodies reactive to purified GPIIb/IIIa subsequently measured by ELISA (Figure 1A). It can be seen that only purified GPIIb/IIIa, and none of the peptides, elicited a significant antibody response.

\section{Prevention of antibody responses to glycoprotein} IIb/IIla by individual peptides

The seven peptides were next tested individually for their ability to prevent the IgG antibody response to GPIIb/IIIa immunization. Different groups of mice were each given one of the peptides, or left untreated, before immunization, and the development of anti-GPIIb/IIIa plasma antibodies compared (Figure 1B). None of the peptides consistently blocked the development of antibody, although there were non-significant trends for lower responses after delivery of peptides 2 (aa6-20), 70 (aa591$605)$ or 82 (aa711-725).
Prevention and inhibition of antibody responses to glycoprotein IIb/IIla by a peptide combination

It has been demonstrated that peptides used in combination can be more effective than individual sequences in preventing or reversing allo- or auto-antibody production. ${ }^{32,34,42,43}$ Peptides 2 (aa6-20) and 82 (aa711-725) were selected to be tested in combination here, since epitopes they contain were previously identified as the most immunodominant, ${ }^{7}$ capable of eliciting Th responses in $65 \%$ of ITP patients tested, and they had also each demonstrated some, albeit variable, inhibition of antibody generation in the individual peptide experiments. It was determined whether prior treatment with an equimolar mixture of peptides 2 (aa6-20) and 82 (aa711-725) prevented induction of the antibody response to immunization with purified GPIIb/IIIa. Given that the antibody levels are measured as relative optical density (OD) values in
A

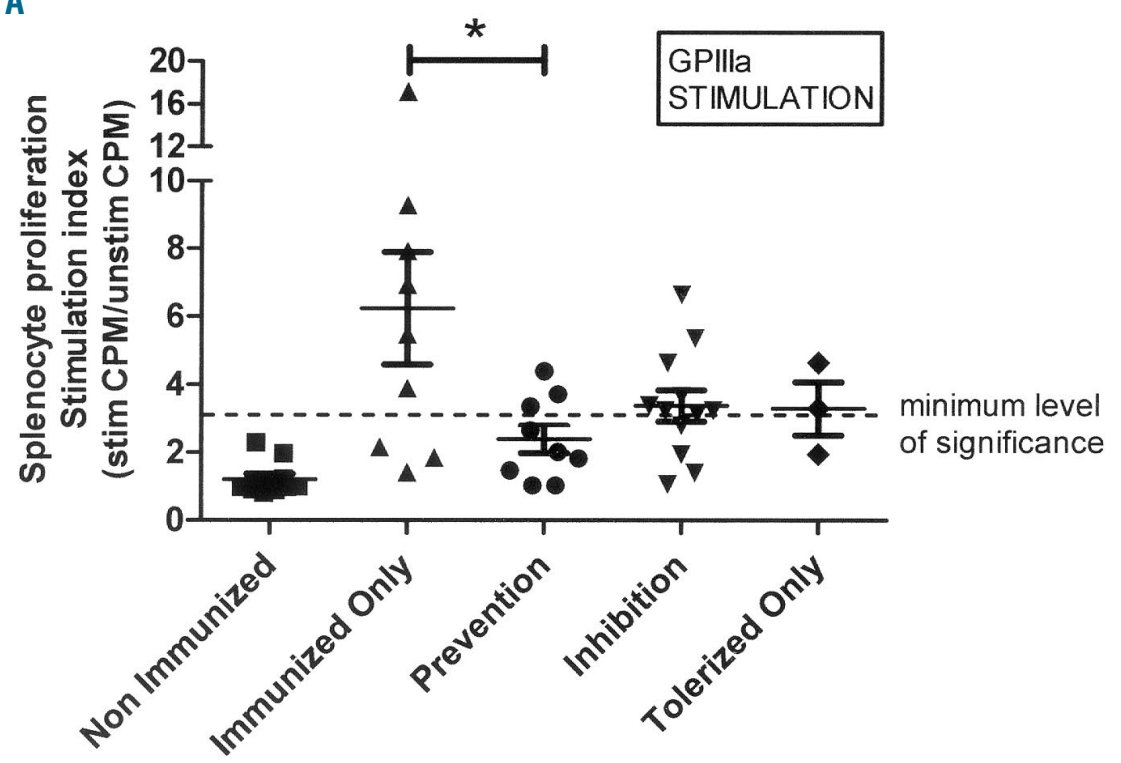

Figure 3. Treatment of HLA-DR15 transgenic mice with glycoprotein Illa peptides containing Th epitopes modulates splenocyte proliferative responses in vitro. Splenocytes were obtained from mice that were untreated controls (nonimmunized); immunized with GPIIb/IIla only (immunized only); pre-treated with a mixture of GPIIb/IIla peptides 2 (aa6-20) and 82 (aa711 725) before GPIIb/IIla immunization (prevention); given the mixture of peptides after GPIIb/IIla immunization (inhibition); or given the mixture of peptides only (tolerized). The panels show proliferation of splenocytes in response to stimulation in vitro with (A) purified GPIIb/IIla, (B) peptide 2 or (C) peptide 82. Data points represent results from individual mice: (A) nonimmunized $(n=10)$, immunized only $(n=9$, prevention $(n=9)$, inhibition $(n=12)$, tolerized $(n=3)$; ( $B$ and $C)$ non-immunized $(n=7)$, immunized only $(n=6)$, prevention $(n=6)$, inhibition $(n=5)$. $* P<0.05, * * P<0.001, t$-test. CPM: counts per minute.
B

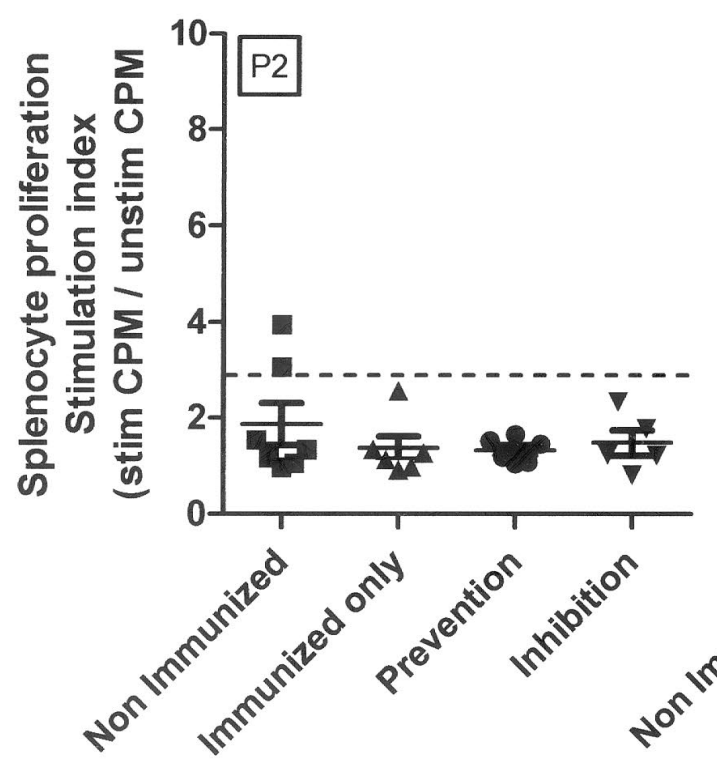

C

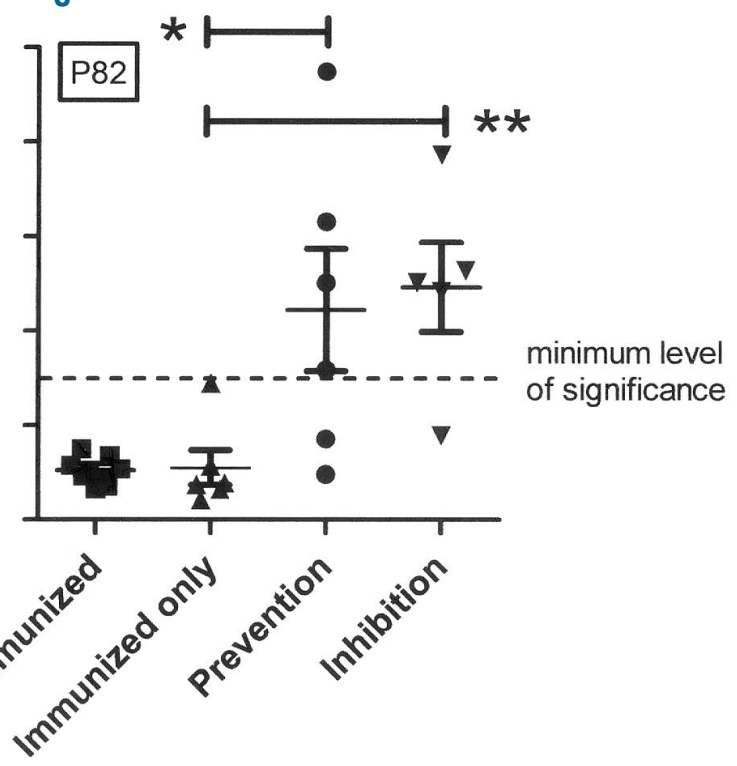


ELISA, and not absolute concentrations, the results were designed to be interpreted as longitudinal studies of mice in each group. In contrast to control mice that received only the immunization, no significant antibody response against GPIIb/IIIa could be detected in animals pre-treated with the peptide combination (Figure 2A, left and middle panels). Extending the time after GPIIb/IIIa immunization by a further 14 days in another group of pre-treated mice $(\mathrm{n}=3)$ saw no increase in antibody levels, consistent with a sustained loss, rather than delay, in responsiveness (mean \pm standard deviation OD: $2.92 \pm 0.09$ at day 42 versus $3.03 \pm 0.1$ at day $56, n=3)$.

Having demonstrated that, unlike either individual peptide, pre-treatment with the combination of peptides 2

A
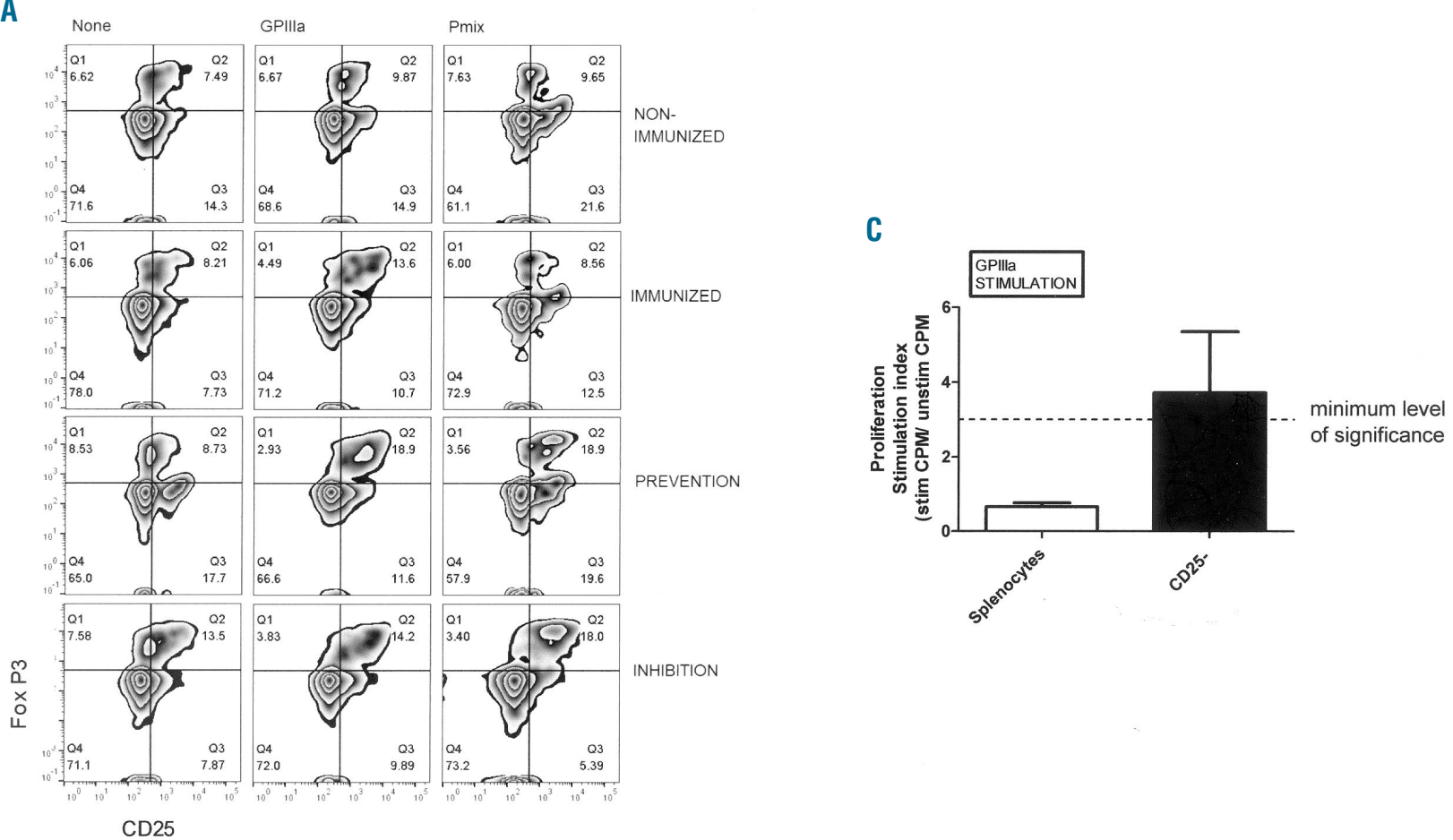

B

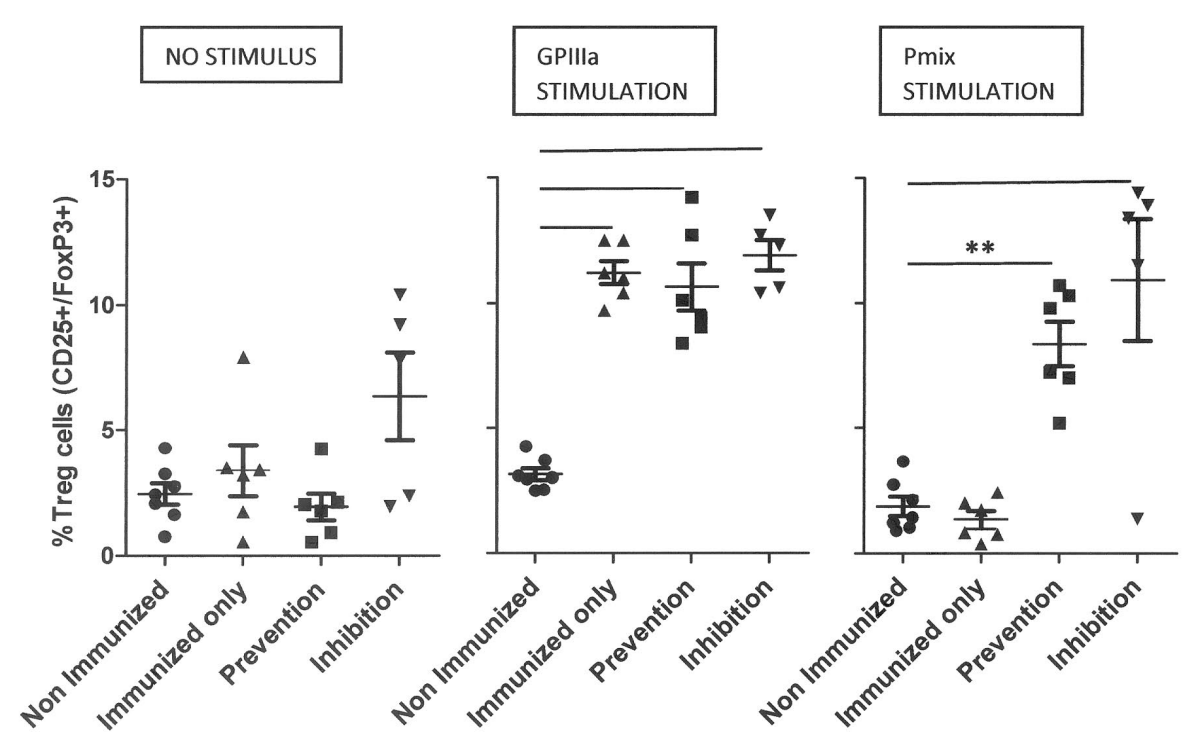

Figure 4. Treatment of HLA-DR15 transgenic mice with glycoprotein Illa peptides containing Th epitopes modulates splenocyte populations with a $\mathrm{CD}^{+} \mathrm{CD} 25^{+}$FoxP $3^{+}$Treg phenotype and suppressive function. Splenocytes were obtained from mice that were untreated controls (non-immunized); immunized with GPIIb/IIla only (immunized only); pre-treated with a mixture of GPIIb/IIla peptides 2 (aa6-20) and 82 (aa711-725) before GPIIb/IIla immunization (prevention); given the mixture of peptides after GPIIb/Illa immunization (inhibition). The cells were left as unstimulated controls (none; no stimulus), or stimulated in vitro with either purified GPIIb/IIla (GPIIla; GPIIla stimulation) or a mixture of all seven GPIIla peptides (Pmix; Pmix stimulation). (A) Representative examples of flow cytometric analyses of CD25 and FoxP3 expression after gating on $\mathrm{CD}^{+}$cells. (B) Proportions of $\mathrm{CD}^{2} 5^{+}$FoxP3 $3^{+}$cells within the splenic $\mathrm{CD} 4^{+}$populations from all the mice. Data points represent results from individual mice (non-immunized) $(n=7)$, immunized only $(n=6)$, prevention $(n=6)$, inhibition $(n=5)$. (C) The effect of depleting CD25+CD4+ cells (CD25-) on the ability of splenocytes from mice in the prevention group $(n=3)$ to make proliferative responses when stimulated with GPIIb/IIla. $* * P<0.005, t-$ test. CPM: counts per minute. 


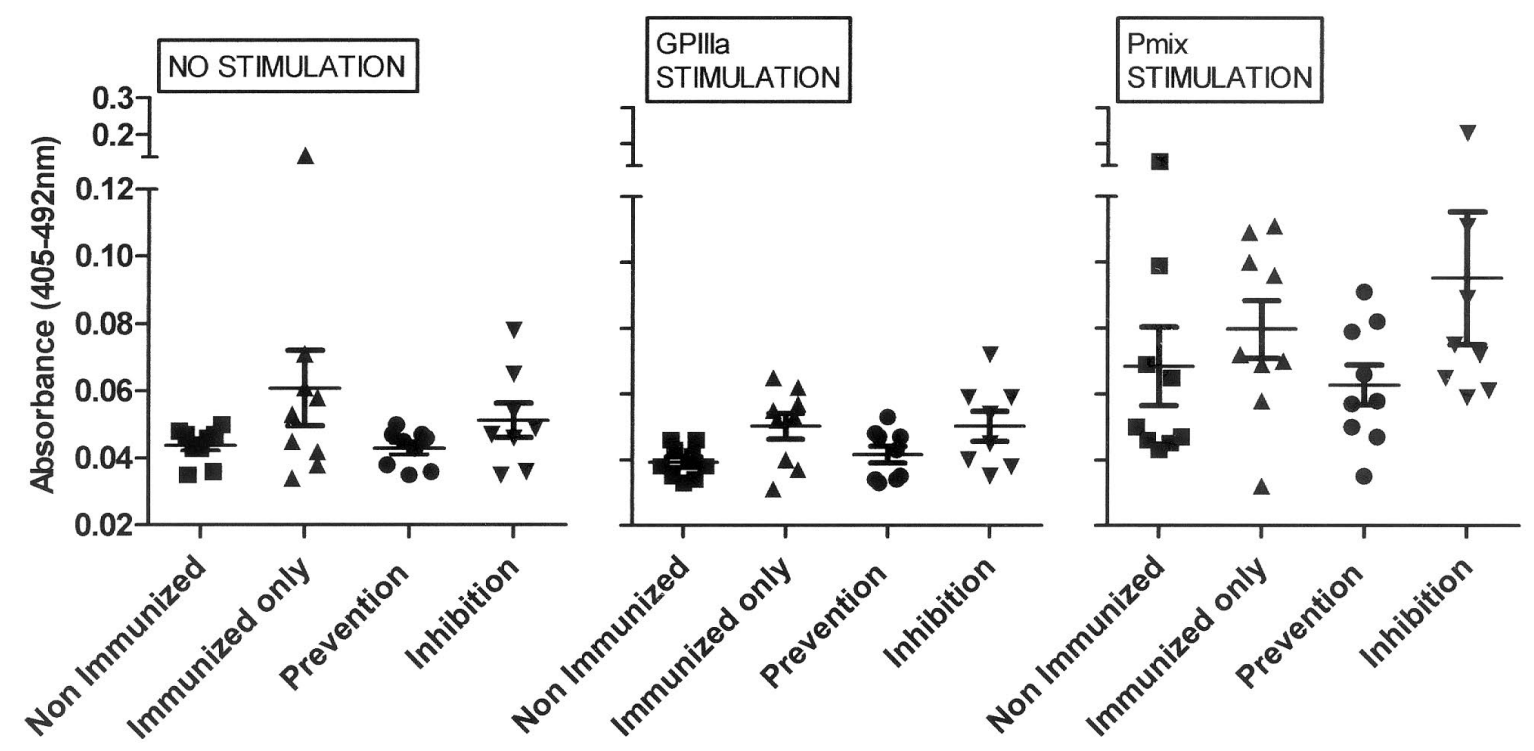

Figure 5. Treatment of HLA-DR15 transgenic mice with glycoprotein Illa peptides containing Th epitopes does not modulate splenocyte interleukin-10 responses in vitro. Splenocytes were obtained from mice that were untreated controls (non-immunized); immunized with GPIIb/IIla only (immunized only); pre-treated with a mixture of GPIIb/IIla peptides 2 (aa6-20) and 82 (aa711-725) before GPIlb/IIla immunization (prevention); or given the mixture of peptides after GPIIb/Illa immunization (inhibition). The cells were left as unstimulated controls (no stimulation; left panel), or stimulated in vitro with either purified GPIlb/Illa (GPIIla stimulation; middle panel) or the mixture of GPIlla peptides (Pmix stimulation; right panel) and the production of interleukin-10 in culture measured by enzyme-linked immunosorbent assay. Data points represent results from individual mice (non-immunized) $(n=9)$, immunized only $(n=9)$, prevention ( $n=9)$, inhibition $n=8)$. In each panel, there are no significant differences in interleukin-10 production between the unimmunized control group and any treated groups ( $t$-test).

(aa6-20) and 82 (aa711-725) could prevent anti-GPIIb/IIIa antibody generation, we next determined whether the mixture could also suppress responses that had already been induced, by administering the peptide product after immunization with GPIIb/IIla (Figure 2A, right panel). As expected, a significant response to immunization was detectable by the time of the peptide administration, but there was a slight, non-significant fall in mean antibody levels over the next 14 days after treatment (mean \pm standard deviation OD: $0.55 \pm 0.1$ at peptide treatment on day 28 versus $0.54 \pm 0.1$ on day $42, \mathrm{n}=8 ; P=0.8)$. By contrast, mean antibody levels continued to rise, modestly but significantly, in the group of control mice that received only immunization (Figure 2A, left panel) (mean \pm standard deviation OD: $0.96 \pm 0.53$ on day 28 versus $1.1 \pm 0.54$ on day $42, \mathrm{n}=14 ; P<0.05)$. Thus, the peptide combination blunted, but did not significantly reverse, ongoing responses to GPIIb/IIIa.

The suppressive effect of treatment of transgenic mice with the peptide combination was specific to GPIIb/IIIa responses, since there was no effect on their ability to make antibody responses to immunization with the unrelated control antigen ovalbumin (Figure 2B).

Prevention and inhibition of T-cell responses to glycoprotein IIb/IIIa by the peptide combination

Class-switched antibody responses classically depend on antigen-specific Th cells, ${ }^{19,20}$ which peptide immunotherapy is intended to target and render unresponsive. ${ }^{28-31}$ To determine the effect of treatment with the combination of GPIIIa peptides 2 (aa6-20) and 82 (aa711725) on Th effector function, we obtained splenocytes from control unimmunized or GPIIb/IIIa-immunized mice, or from animals that had received the peptides either before or after immunization, and compared their ability to proliferate in vitro when stimulated with purified GPIIb/IIIa (Figure 3A). As expected, splenocytes from mice that been immunized with GPIIb/IIIa proliferated in response to the antigen, whereas there were no responses in control, unimmunized animals. Flow cytometric analyses demonstrated that $\mathrm{T}$ cells with the $\mathrm{CD} 4^{+}$helper phenotype predominated in the proliferating cultures $(>70 \%$ in all cases, $n=6$ ). Proliferation against GPIIb/IIIa was significantly reduced when immunized mice had been pretreated with the combination of peptides 2 (aa6-20) and 82 (aa711-725), and there was also a non-significant trend for responses to be inhibited when mice were treated with the peptides after immunization.

Splenocyte responsiveness to the individual GPIIIa peptides 2 (aa6-20) or 82 (aa711-725) was also assayed (Figure 3B). Peptide 2 (aa6-20) elicited no consistent proliferative responses in any group, but peptide 82 (aa711-725) demonstrated significant stimulatory ability in both groups of animals that had received the peptide combination in addition to immunization.

\section{Induction of regulatory T cells by the peptide combination}

Having demonstrated that treatment with a combination of GPIIIa peptides can suppress both antibody and effector T-cell responses to GPIIb/IIIa immunization, we determined whether this was associated with induction of Treg cells. The proportions of cells exhibiting the $\mathrm{CD} 25^{+} \mathrm{FoxP}^{+}$Treg phenotype within the $\mathrm{CD}^{+}$splenocyte population were compared in control, unimmunized and GPIIb/IIIa-immunized mice, and in animals that had received the peptide mixture either before or after immunization. Treg cells were enumerated both when spleno- 
cytes had received no further stimulus in vitro, and after incubation with either purified GPIIb/IIIa, or the peptide mix. Figure 4A illustrates examples of contour plots obtained from individual animals from each group, and Figure 4B summarizes all the data. Without stimulation in culture, the proportions of cells with the Treg phenotype were low, typically $<5 \%$ of $\mathrm{CD}^{+}$cells, irrespectively of whether the mice had been immunized or received peptide. However, after in vitro stimulation with purified GPIIb/IIIa the Treg population increased, typically to $>10 \%$ of $\mathrm{CD}^{+}$cells, in all the immunized groups, both peptide-treated and -untreated, reaching proportions of Treg that were significantly higher than those seen in nonimmunized controls. When stimulated in vitro with the peptide mix, increases in Treg were seen in mice that had received peptide either before or after immunization, but not in animals given only the immunization. Overall, the observed inhibition of antibody and Th effector function by peptide therapy is therefore associated with recruitment of cells with a Treg phenotype, which differ in responsiveness from those induced by the purified fulllength antigen. This is consistent with induction of suppression to GPIIb/IIIa by peptide-specific Treg. It was confirmed that Treg cells contribute to the suppressive effect in peptide-treated mice since splenocyte proliferative responsiveness to GPIIb/IIIa was restored by depletion of the CD25+ $\mathrm{T}$-cell population that contains the Treg cells (Figure 4C).

Production of the regulatory cytokine IL-10 is not necessarily associated with the classic $\mathrm{CD}_{2} 5^{+} \mathrm{FoxP}^{+}$Treg population, but represents another mechanism by which effector responses can be downregulated following peptide immunotherapy. ${ }^{19-23,28,29,44}$ When we measured production of IL-10 by splenocytes (Figure 5), there were no differences between levels of the cytokine in cultures from mice that had been non-immunized, immunized, or given immunization and peptides, although across all groups there was a trend for IL-10 production to be higher when splenocytes were stimulated with the peptide mix compared to unstimulated or GPIIb/IIIa-stimulated cultures. Therefore, in this model of peptide therapy, there is little evidence for IL-10 having a role in suppression.

\section{Discussion}

As part of a strategy to develop and evaluate specific peptide therapy for ITP, this study determined the ability of sequences containing immunodominant helper epitopes to suppress responses to the major human platelet autoantigen GPIIb/IIla by humanized mice expressing HLA-DR15. None of seven GPIIIa peptides, when tested individually, was able reliably to inhibit antibody responses by the mice to immunization with purified GPIIb/IIIa, but the combination of peptides 2 (aa6-20) and 82 (aa711725 ) did suppress the development of antibodies and proliferative effector $\mathrm{T}$-cell responses. These inhibitory effects were associated with induction of a specific population of Treg cells, and raise the prospect that the peptide combination may be effective in ameliorating ITP in patients.

Previous studies in other diseases have suggested that combinations of peptides are markedly more effective than individual sequences in suppressing pathogenic immune responses in murine models, ${ }^{32,3,4,42,43}$ and several of these combinations have progressed into the clinic, with promising results recently reported from human trials. These include phase I trials of a combination of three HLA-DQ2-restricted immunodominant peptides in the ImmusanT product Nexvax2 to treat celiac disease, ${ }^{45}$ phase Ila trials of a mixture of four myelin peptides in the Apitope product ATX-MS-1467 in patients with multiple sclerosis (ClinicalTrials.gov Identifier: NCT01973491), and a phase I trial in type 1 diabetes of the product MultiPepT1De containing proinsulin sequences. ${ }^{46}$ Combinations of peptides may be more effective than individual sequences in triggering therapeutic suppression for a number of reasons. First, different class II molecules vary in their peptide binding preferences ${ }^{47}$ and so mixtures of peptides can maximize the likelihood of effective presentation to $\mathrm{CD}^{+} \mathrm{T}$ cells in HLA-disparate patient populations..$^{29-31}$ However, this does not account for the superior efficacy of the combination of peptides 2 (aa6-20) and 82 (aa711-725) versus the individual sequences in the current murine model, in which only HLA-DR15 is available. Here, a second explanation, that additional peptides interact with a wider pool of $\mathrm{T}$-cell specificities and are therefore more likely to tip the balance of the response towards regulation, is more relevant. ${ }^{29-31,34}$ In vivo studies such as these provide the opportunity to catalogue the complex immune properties that therapeutic peptides can exhibit alone or in combination. Individual peptides can induce different balances between effector and regulatory $\mathrm{T}$ cells, ${ }^{21,22}$ yet can synergize in suppression, as illustrated here by the ability of peptide 2 (aa6-20), but not 82 (aa711$725)$, to stimulate the proliferation of splenocytes, when mice need to be given both peptides to inhibit GPIIb/IIIa responses. The combination of peptides 2 (aa6-20) and 82 (aa711-725) is attractive as a candidate product to treat ITP, not only because of the current demonstration of efficacy in a pre-clinical model, but also because the sequences appear promiscuous in their ability to be presented by different HLA-DR molecules, and are together recognized by $\mathrm{T}$ cells from the majority of patients. The finding that the inhibitory effects of the peptides are limited to responses to GPIIb/IIIa, and not control antigen, demonstrates specificity of suppression and suggests that immunity to infection would not be compromised by treatment.

In many animal models of immune-mediated disease, and clinical investigations, the efficacy of peptide immunotherapy is associated with suppression of effector $\mathrm{T}$ cells and induction of Treg populations. ${ }^{29-32,43-46}$ The approach is attractive for development as a novel treatment for ITP since the disease is associated with an impairment of $\mathrm{CD}^{+}{ }^{+} \mathrm{CD} 25^{+} \mathrm{FoxP3}^{+}$Treg cells, with their frequency being reduced in the circulation, spleen and bone marrow., ${ }^{2,16-18}$ Dysregulation of Treg cells is also restored in line with platelet counts after treatment with dexamethasone, rituximab or thrombopoietin., ${ }^{2,4}$ Analysis of a SCID murine model of ITP, which is induced by adoptive transfer of splenocytes from CD61\% mice that have been immunized with $\mathrm{CD}^{+} 1^{+}$platelets, further demonstrated a dysregulation of $\mathrm{CD} 4^{+} \mathrm{CD} 25^{+} \mathrm{FoxP}^{+}$Treg cells. ${ }^{4}$ These mice were successfully treated with intravenous immunoglobulins, which normalized both platelet and Treg counts. ${ }^{48}$ The suppression of antibody responses to GPIIb/IIIa in HLA-DR transgenic mice reported here now raises the prospect that Treg can be boosted therapeutically in ITP, with populations of antigen-responsive cells with a $\mathrm{CD} 4^{+} \mathrm{CD} 25^{+} \mathrm{FoxP}^{+}$Treg phenotype induced in the 
spleens after specific peptide therapy. Treg cells can suppress antibody responses not only by blocking Th activity, but also by direct effects on B cells. ${ }^{40}$ Unlike some other examples of successful peptide therapy, ${ }^{28-31,44}$ suppression in our model was not associated with IL-10 responses, suggesting it is mediated by the $\mathrm{CD} 4^{+} \mathrm{CD} 25^{+} \mathrm{FoxP} 3^{+}$Treg we observed, which are classically cytokine independent, rather than by other cells such as the T regulatory $1(\operatorname{Tr} 1)$ type. One notable feature of our study is that, while both immunization of mice with purified GPIIb/IIIa, and treatment with the peptide combination, induced Treg phenotype cells, the populations differed in specificity. This difference is demonstrated by the ability of the splenic Treg phenotype population induced in immunized mice to respond to GPIIb/IIIa, but not the peptides, and suggests an explanation for the success of immunization, and the ability of splenocytes to proliferate, in the face of such a population. Thus, the cells with the Treg phenotype induced as part of the response to GPIIb/IIIa are unable to block immunization, at least within the timeframe of our experiments, but the peptides tip the balance to suppression by recruiting more effective, or additional, Treg cells not induced by the antigen alone. It is recognized that antigens and peptides can induce both effector and regulatory cells, and that an evolving balance between these populations, particularly inter-conversion of Teff and Treg, determines the functional outcome..$^{21,22}$ Our approach to peptide therapy demonstrated high efficacy in preventing antibody and T-cell responses to GPIIb/IIIa when the peptides were given prior to immunization, and although developing responses were blunted when mice were treated after immunization, antibody levels did not fall. This may reflect a relatively slow decay of established responses in the face of regulation, which, if necessary, could be augmented by additional peptide doses ${ }^{43}$ since our regimen for combination peptide therapy was a single subcutaneous injection, for easy translation to clinical practice. Alternatively, peptide therapy could also be combined with existing, more rapidly acting approaches, such as use of the biologic rituximab to target B cells directly, while peptide-induced Treg cells block longer-term recruitment to the immune response. Solubility is a key feature in the efficient manufacture of pure peptides, and in their ability to induce regulation. ${ }^{28,29,34,35}$ Although peptide 2 (aa6-20) needed no modification to meet this criterion, we extended the sequence of peptide 82 (aa711-725) with an arginine-lysine wrapper in order to ensure adequate solubility, so that the combined peptides were appropriate for further product development.

The current results add to the body of work indicating that the manipulation of Treg cells offers an effective strategy for ameliorating ITP and other autoimmune antibodymediated diseases,,$^{16-22,48}$ and the data demonstrate that this goal could be achieved by peptide immunotherapy. The ability of a combination of peptides to suppress antibody and T-cell responses to GPIIb/IIIa, and to induce Treg, in our pre-clinical model provides further justification for human clinical trials of this approach in ITP. Differences between species inevitably present a risk that positive results from murine studies do not translate to human patients, but we have reduced this by testing mice with partially humanized immune systems, and by asking highly defined questions as to the ability of GPIIIa peptides presented in vivo by human MHC class II molecules to induce suppression. A product containing GPIIIa peptides 2 (aa6-20) and 82 (aa711-725) therefore represents the basis for development, with the initial indication being those ITP patients in whom conventional immunosuppressive treatments have failed.

\section{Funding}

The study was funded by grants from the Medical Research Council (UK) Confidence in Concept, the Scottish National Blood Transfusion Service and the Wellcome Trust (UK).

\section{Acknowledgments}

We would like to acknowledge the assistance of Iain Fraser Cytometry Centre at the University of Aberdeen.

\section{References}

1. Semple JW. Immune pathophysiology of autoimmune thrombocytopenic purpura. Blood Rev. 2002;16(1):9-12.

2. McKenzie CG, Guo L, Freedman J, Semple JW. Cellular immune dysfunction in immune thrombocytopenia (ITP). Br J Haematol. 2013;163(1):10-23

3. Cines DB, Cuker A, Semple JW. Pathogenesis of immune thrombocytopenia. Presse Med. 2014;43(4 Pt 2):49-59.

4. Zufferey A, Kapur R, Semple JW. Pathogenesis and therapeutic mechanisms in immune thrombocytopenia (ITP). J Clin Med. 2017;6(2).pii:E16.

5. Hürlimann-Forster M, Steiner B, von Felten A. Quantitation of platelet-specific autoantibodies in platelet eluates of ITP patients measured by a novel ELISA using the purified glycoprotein complexes GPIIb/IIIa and GPIb/IX as antigens. Br J Haematol. 1997:98(2):328-335.

6. McMillan R. Autoantibodies and autoanti- gens in chronic immune thrombocytopenic purpura. Semin Hematol. 2000;37(3):239248.

7. Sukati H, Watson HG, Urbaniak SJ, Barker RN. Mapping helper T-cell epitopes on platelet membrane glycoprotein IIIa in chronic autoimmune thrombocytopenic purpura. Blood. 2007;109(10):4528-4538.

8. Chang M, Nakagawa PA, Williams SA, et al Immune thrombocytopenic purpura (ITP) plasma and purified ITP monoclonal autoantibodies inhibit megakaryocytopoiesis in vitro. Blood. 2003;102(3):887-895

9. McMillan R, Wang L, Tomer A, Nichol J, Pistillo J. Suppression of in vitro megakaryocyte production by antiplatelet autoantibodies from adult patients with chronic ITP. Blood. 2004;103(4):1364-1369.

10. Olsson B, Andersson PO, Jernas M, et al. Tcell-mediated cytotoxicity toward platelets in chronic idiopathic thrombocytopenic purpura. Nat Med. 2003;9(9):1123-1124.

11. Zhang F, Chu X, Wang L, et al. Cell-mediated lysis of autologous platelets in chronic idiopathic thrombocytopenic purpura. Eur J
Haematol. 2006;76(5):427-431

12. Roark JH, Bussel JB, Cines DB, Siegel DL. Genetic analysis of autoantibodies in idiopathic thrombocytopenic purpura reveals evidence of clonal expansion and somatic mutation. Blood. 2002;100(4):1388-1398.

13. Semple JW, Freedman J. Increased antiplatelet T-helper lymphocyte reactivity in patients with autoimmune thrombocytopenia. Blood. 1991:78(10):2619-2625.

14. Kuwana M, Kaburaki J, Ikeda Y. Autoreactive T cells to platelet GPIIb-IIIa in thrombocytopenic purpura. J Clin Invest. 1998;102(7):1393-1402.

15. Kuwana M, Kaburaki J, Kitasato $H$, Miyako K. Immunodominant epitopes on glycoprotein IIb-IIIa recognized by autoreactive $\mathrm{T}$ cells in patients with immune thrombocytopenic purpura. Blood. 2001; 98(1):130-139.

16. Yazdanbakhsh K. Imbalanced immune homeostasis in immune thrombocytopenia. Semin Hematol. 2016;53(Suppl 1):S16-S19.

17. Semple JW. 2003. T cell and cytokine abnormalities in patients with autoimmune 
thrombocytopenic purpura. Transfus Apher Sci. 2003;28(3):237-242.

18. Aslam R, Hu Y, Gebremeskel S, Segel GB, et al. Thymic retention of $\mathrm{CD} 4+\mathrm{CD} 25+\mathrm{FoxP} 3+\mathrm{T}$ regulatory cells is associated with their peripheral deficiency and thrombocytopenia in a murine model of immune thrombocytopenia. Blood. 2012;120(10):2127-2132.

19. Elson CJ, Barker RN. Helper T cells in antibody-mediated, organ-specific autoimmunity. Curr Opin Immunol. 2000;12(6):664-669.

20. Barker RN, Vickers MA, Ward FJ. Controlling autoimmunity--lessons from the study of red blood cells as model antigens. Immunol Lett. 2007;108(1):20-26.

21. Hall AM, Ward FJ, Vickers MA, Stott LM, Urbaniak SJ, Barker RN. Interleukin-10mediated regulatory $\mathrm{T}$-cell responses to epitopes on a human red blood cell autoantigen. Blood. 2002;100(13):4529-4536.

22. Ward FJ, Hall AM, Cairns LS, et al. Clonal regulatory $\mathrm{T}$ cells specific for a red blood cell autoantigen in human autoimmune hemolytic anemia. Blood. 2008;111(2):680687.

23. Neunert C, Lim W, Crowther M, Cohen A, Solberg L Jr, Crowther MA. The American Society of Hematology 2011 evidence-based practice guideline for immune thrombocytopenia. Blood. 2011;117(16):4190-4207.

24. Lozano ML, Revilla N, Gonzalez-Lopez TJ, et al. Real-life management of primary immune thrombocytopenia (ITP) in adult patients and adherence to practice guidelines. Ann Hematol. 2016;95(7):1089-1098.

25. Frederiksen H, Maegbaek ML, Nørgaard M. Twenty-year mortality of adult patients with primary immune thrombocytopenia: a Danish population-based cohort study. Br J Haematol. 2014;166(2):260-267.

26. Ghadaki B, Nazi I, Kelton JG, Arnold DM. Sustained remissions of immune thrombocytopenia associated with the use of thrombopoietin receptor agonists. Transfusion. 2013;53(11):2807-2812

27. Nishimoto T, Numajiri $M$, Nakazaki $H$, Okazaki Y, Kuwana M. Induction of immune tolerance to platelet antigen by short-term thrombopoietin treatment in a mouse model of immune thrombocytopenia. Int J Hematol. 2014;100(4):341-344

28. Larché M, Wraith DC. Peptide-based thera- peutic vaccines for allergic and autoimmune diseases. Nat Med. 2005;11(4 Suppl):S69-76.

29. Sabatos-Peyton CA, Verhagen J, Wraith DC. Antigen-specific immunotherapy of autoimmune and allergic diseases. Curr Opin Immunol. 2010;22(5):609-615

30. Hoffmann HJ, Valovirta E, Pfaar O, et al. Novel approaches and perspectives in allergen immunotherapy. Allergy. 2017;72(7): 1022-1034.

31. Larché M. Mechanisms of peptide immunotherapy in allergic airways disease. Ann Am Thorac Soc. 2014;11(Suppl 5):S292 296.

32. Hirsch DL, Ponda P. Antigen-based immunotherapy for autoimmune disease: current status. Immunotargets Ther 2014:4:1-11

33. Hall AM, Cairns LS, Altmann DM, Barker $\mathrm{RN}$, Urbaniak SJ. Immune responses and tolerance to the $\mathrm{RhD}$ blood group protein in HLA-transgenic mice. Blood. 2005;105(5): 2175-2179.

34. Hall LS, Hall AM, Pickford W, Vickers MA Urbaniak SJ, Barker RN. Combination peptide immunotherapy suppresses antibody and helper $\mathrm{T}$-cell responses to the $\mathrm{RhD}$ protein in HLA-transgenic mice. Haematologica. 2014;99(3):588-596.

35. Shen CR, Youssef AR, Devine A, et al. Peptides containing a dominant T-cell epitope from red cell band 3 have in vivo immunomodulatory properties in NZB mice with autoimmune hemolytic anemia. Blood. 2003;102(10):3800-3806.

36. Negi RR, Bhoria P, Pahuja A, et al Investigation of the possible association between the HLA antigens and idiopathic thrombocytopenic purpura (ITP). Immunol Invest. 2012:41(2):117-128.

37. Nomura S, Matsuzaki T, Ozaki Y, et al. Clinical significance of HLA-DRB1*0410 in Japanese patients with idiopathic thrombocytopenic purpura. Blood. 1998;91(10):36163622 .

38. Bessos H, Perez S, Armstrong-Fisher S, Urbaniak S, Turner M. The development of a quantitative ELISA for antibodies against human platelet antigen type 1a. Transfusion. 2003;43(3):350-356

39. Ellmerich S, Takacs K, Mycko M, et al. Disease-related epitope spread in a humanized $\mathrm{T}$ cell receptor transgenic model of mul- tiple sclerosis. Eur I Immunol 2004;34(7):1839-1848.

40. Nishimura E, Sakihama T, Setoguchi R, Tanaka K, Sakaguchi S. Induction of antigenspecific immunologic tolerance by in vivo and in vitro antigen-specific expansion of naturally arising Foxp3+CD25+CD4+ regulatory T cells. Int Immunol. 2004;16(8):11891201

41. Devereux G, Hall AM, Barker RN Measurement of T-helper cytokines secreted by cord blood mononuclear cells in response to allergens. I Immunol Methods. 2000;234(1-2):13-22.

42. Mackenzie KJ, Fitch PM, Leech MD, et al. Combination peptide immunotherapy based on $T$ cell epitope mapping reduces allergen-specific IgE and eosinophilia in allergic airway inflammation. Immunology. 2013;138(3):258-268.

43. Gibson VB, Nikolic T, Pearce VO, Demengeot J, Roep BO, Peakman $M$ Proinsulin multi-peptide immunotherapy induces antigen-specific regulatory $\mathrm{T}$ cells and limits autoimmunity in a humanized model. Clin Exp Immunol. 2015;182(3):251 260.

44. Nicolson KS, O'Neill EJ, Sundstedt A Streeter HB, Minaee S, Wraith DC. Antigeninduced IL-10+ regulatory $T$ cells are independent of CD25+ regulatory cells for their growth, differentiation, and function. J Immunol. 2006:176(9):5329-5337.

45. Goel G, King T, Daveson AJ, et al. Epitopespecific immunotherapy targeting CD4-positive $\mathrm{T}$ cells in coeliac disease: two randomised, double-blind, placebo-controlled phase 1 studies. Lancet Gastroenterol Hepatol. 2017;2(7):479-493.

46. Alhadj Ali M, Liu YF, Arif S, et al. Metabolic and immune effects of immunotherapy with proinsulin peptide in human newonset type 1 diabetes. Sci Transl Med. 2017;9(402).pii:eaaf7779.

47. Singh H, Raghava GPS. ProPred: prediction of HLA-DR binding sites. Bioinformatics. 2001;17(12):1236-1237.

48. Aslam R, Hu Y, Gebremeskel S, et al Thymic retention of CD4+CD25+FoxP3+ regulatory cells is associated with their peripheral deficiency and thrombocytopenia in a murine model of immune thrombocytopenia. Blood. 2012;120(10):2127-2132. 